\title{
Carbonation Coefficients from Concrete Made with High-Absorption Limestone Aggregate
}

\author{
Eric I. Moreno \\ College of Engineering, Universidad Autónoma de Yucatán, Avenida Industrias No Contaminantes s/n por Periférico Norte, Mérida, \\ YUC, CP 97110, Mexico \\ Correspondence should be addressed to Eric I. Moreno; emoreno@uady.mx
}

Received 31 May 2013; Accepted 28 August 2013

Academic Editor: Amit Bandyopadhyay

Copyright (C) 2013 Eric I. Moreno. This is an open access article distributed under the Creative Commons Attribution License, which permits unrestricted use, distribution, and reproduction in any medium, provided the original work is properly cited.

\begin{abstract}
Normal aggregates employed in concrete have absorption levels in the range of $0.2 \%$ to $4 \%$ for coarse aggregate and 0.2 to $2 \%$ for fine aggregate. However, some aggregates have absorption levels above these values. As the porosity of concrete is related to the porosity of both the cement paste and the aggregate and the carbonation rate is a function, among other things, of the porosity of the material, there is concern about the effect of this high porosity material in achieving good quality concrete from the durability point of view. Thus, the objective of this investigation was to study the carbonation rates of concrete specimens made with highabsorption limestone aggregate. Four different water/cement ratios were used, and cylindrical concrete specimens were exposed to accelerated carbonation. High porosity values were obtained for concrete specimens beyond the expected limits for durable concrete. However, carbonation coefficients related to normal quality concrete were obtained for the lowest water/cement ratio employed suggesting that durable concrete may be obtained with this material despite the high porosity.
\end{abstract}

\section{Introduction}

Concrete is the most used material for infrastructure development. However, durability of these structures is one of the main concerns, as the expected service life is approaching more than a hundred years. Among the known durability issues for concrete, corrosion of reinforcing steel is the main problem. In concrete structures, reinforcing steel is protected due to the high alkaline environment provided by the pore solution ( $\mathrm{pH}>12.5$ units). However, it may corrode if the protection is lost. The protection may be lost due to chloride attack or due to the neutralization of the concrete pore solution surrounding the reinforcing steel. This neutralization of the pore solution is also called concrete carbonation. Concrete carbonation is the result of the reaction of hydrated cement compounds with atmospheric $\mathrm{CO}_{2}$. Carbonation reduces the $\mathrm{pH}$ of the concrete pore solution ( $\mathrm{pH} \approx 8$ units), developing uniform corrosion in the reinforcing steel. In places with tropical climate, atmospheric conditions may encourage the $\mathrm{CO}_{2}$ aggressiveness [1]. However, the carbonation rate depends on several factors [2] such as the type and amount of cement, porosity of the material [3], and amount of pozzolanic additions [4].

The porosity of concrete is related to the porosity of both the cement paste and the aggregate and the proper compaction during casting. The porosity of the cement paste is related to the water/cement ratio and the degree of hydration. From the durability point of view, it is accepted that the porosity of the cement paste is the one that controls the porosity of concrete. According to the literature [5], concrete's porosity above $15 \%$ is an indication of bad quality and below $10 \%$ is an indication of good quality.

Normal aggregates used in concrete have absorption levels in the range of $0.2 \%$ to $4 \%$ for coarse aggregate and 0.2 to $2 \%$ for fine aggregate [6]. However, some limestone aggregates have absorption levels above these values [7]. And due to the high-absorption characteristics of the aggregate, concrete made with this material has porosity values above $15 \%$, thus suggesting bad quality concrete from the durability point of view.

One way to prove if this material is suitable for durable concrete structures is by determining the carbonation coefficient of the material. However, as concrete carbonation 
proceeds at a very low rate, the use of an accelerated carbonation chamber is required.

Therefore, the objective of this investigation was to study the carbonation rates of concrete specimens made with highabsorption limestone aggregate.

\section{Methodology}

2.1. Specimens and Materials. Four water/cement (w/c) ratios were used $(0.80,0.70,0.62$, and 0.55$)$. The cementitious material was Ordinary Portland Cement with no mineral additions. Crushed limestone of high absorption was used as coarse and fine aggregate (Table 1). Mixtures were designed according to the ACI specifications [8], and casting was made following the ASTM standards (Table 2) [9].

Concrete specimens were cylindrical in shape of different size: $300 \mathrm{~mm}$ by $150 \mathrm{~mm}$ for compressive strength tests, $200 \mathrm{~mm}$ by $100 \mathrm{~mm}$ for porosity tests, and $150 \mathrm{~mm}$ by $75 \mathrm{~mm}$ for carbonation tests. After casting, the curing period consisted of 28 days of water immersion. Once cured, the specimens were allowed to condition at lab environment prior to undergoing accelerated testing. The conditioning period was 80 days. Following conditioning, the specimens were placed in a $4 \% \mathrm{CO}_{2}$ environment in order to accelerate the carbonation process for $\sim 100$ days, except for mixture 0.55 that was exposed for 176 days.

2.2. Carbonation Depth Measurements. The progress of the carbonation depth was determined by spraying a $1 \%$ phenolphthalein solution on top of a freshly broken concrete surface following the RILEM criteria [10]. For each determination, two specimens were removed from the carbonation chamber per w/c. After that, an $\sim 50 \mathrm{~mm}$ slice was split from each specimen using a chisel and a hammer. After applying the acid-base indicator, the measurements were performed using a digital caliper. Eight measurements were taken in the more suitable half cylinder as the cuts were irregular. Each measurement was corrected from radial measurements in a cylinder into carbonation depth measurements that would be obtained in a semi-infinite plane [3]. Once corrected, the average was obtained for each cylinder, and the result was averaged with the result from the other cylinder, obtaining an average from each pair of cylinders. After taking the carbonation measurements, the remaining portion of the concrete cylinders was placed back in the chamber.

In addition, a first carbonation depth measurement was performed using the external control specimens. This test was made after the conditioning period was finished and prior to placing the specimens in the carbonation chamber in order to determine the progress of the carbonation front during the conditioning period. In turn, the first carbonation depth measurement was used to correct the carbonation coefficient during the accelerated carbonation period.

\section{Results}

Table 3 shows the results from the compressive strength, porosity tests, and fresh concrete slump. The compressive
TABLE 1: Materials properties.

\begin{tabular}{lcc}
\hline Material & Property & Value \\
\hline & Maximum size & $3 / 4$ \\
Coarse aggregate & Specific weight & 2.4 \\
& Lose unit weight & $1,180 \mathrm{~kg} / \mathrm{m}^{3}$ \\
& Compact unit weight & $1,290 \mathrm{~kg} / \mathrm{m}^{3}$ \\
& Absorption & $5.5 \mathrm{w} / \mathrm{o}$ \\
\hline \multirow{3}{*}{ Fine aggregate } & Specific weight & 2.44 \\
& Fineness modulus & 2.6 \\
& Absorption & $4.7 \mathrm{w} / \mathrm{o}$ \\
\hline
\end{tabular}

TABLE 2: Mixture design (kg).

\begin{tabular}{lcccc}
\hline w/c ratio & Water & Cement & $\begin{array}{c}\text { Coarse } \\
\text { aggregate }\end{array}$ & $\begin{array}{c}\text { Fine } \\
\text { aggregate }\end{array}$ \\
\hline 0.80 & 230 & 288 & 749 & 847 \\
0.70 & 235 & 336 & 749 & 795 \\
0.62 & 235 & 379 & 749 & 764 \\
0.55 & 235 & 427 & 749 & 725 \\
\hline
\end{tabular}

strength results were above the nominal values, particularly for $0.80 \mathrm{w} / \mathrm{c}$ mixture. The porosity values were high, however, in the expected range for the type of high-absorption aggregate used and with little difference among the different mixtures [7]. Concrete slump was in the expected range of $10 \mathrm{~cm} \pm 2$; however, $0.55 \mathrm{w} / \mathrm{c}$ mixture had the smallest slump, and $0.62 \mathrm{w} / \mathrm{c}$ mixture had the highest.

Table 4 shows the results from the carbonation depth measurements. As the diameter was $75 \mathrm{~mm}$, the specimens were fully carbonated when the carbonation depth was $37.5 \mathrm{~mm}$. Due to the fact that mixture 0.55 was a better mixture than the others, carbonation depth was not determined at 51 days but at 112 days, instead. By day 51, mixtures 0.7 and 0.8 were fully carbonated.

\section{Discussion}

From the data in Table 4, the average carbonation coefficients at $4 \% \mathrm{CO}_{2}$ were estimated. The data is presented in Table 5. Usually, carbonation is modeled as

$$
x=k \sqrt{t}
$$

where $t$ is the time of exposure, $x$ is the carbonation depth at time $t$, and $k$ is the carbonation coefficient. However, when initial carbonation exists previous to accelerated carbonation, then, the carbonation coefficient at $4 \% \mathrm{CO}_{2}$ may be obtained from [3]

$$
k_{4 \%}=\sqrt{\frac{\left(x^{2}-x_{0}^{2}\right)}{t}},
$$

where $t$ is the time of accelerated exposure, $x$ is the carbonation depth at time $t$, and $x_{0}$ is the initial carbonation 
TABLE 3: Concrete properties.

\begin{tabular}{lcccccc}
\hline w/c ratio & $\begin{array}{c}\text { Designed strength } \\
\text { MPa }\end{array}$ & $\begin{array}{c}\text { Compressive strength } \\
\mathrm{MPa}\end{array}$ & $\begin{array}{c}\text { Volumetric weight } \\
\mathrm{kg} / \mathrm{m}^{3}\end{array}$ & $\begin{array}{c}\text { Air } \\
\%\end{array}$ & $\begin{array}{c}\text { Slump } \\
\mathrm{cm}\end{array}$ & $\begin{array}{c}\text { Porosity } \\
\%\end{array}$ \\
\hline 0.80 & 15 & 18.0 & 2,120 & 2.8 & 10 & 23.4 \\
0.70 & 20 & 21.7 & 2,120 & 2.8 & 10 & 23.1 \\
0.62 & 25 & 26.1 & 2,120 & 2.9 & 11 & 24.1 \\
0.55 & 30 & 30.9 & 2,160 & 2.9 & 22.9 \\
\hline
\end{tabular}

TABLE 4: Carbonation depth measurements and standard deviations (mm).

\begin{tabular}{|c|c|c|c|c|c|c|c|c|}
\hline \multirow{3}{*}{ Mixture } & \multicolumn{8}{|c|}{ Days of exposure at $4 \% \mathrm{CO}_{2}$} \\
\hline & \multicolumn{2}{|c|}{15} & \multicolumn{2}{|c|}{37} & \multicolumn{2}{|c|}{51} & \multicolumn{2}{|c|}{112} \\
\hline & $x$ & $\sigma$ & $x$ & $\sigma$ & $x$ & $\sigma$ & $x$ & $\sigma$ \\
\hline 0.80 & 15.7 & 1.0 & 37.5 & - & \multicolumn{2}{|c|}{-} & \multicolumn{2}{|c|}{-} \\
\hline 0.70 & 13.7 & 1.6 & 24.2 & 1.4 & 37.5 & - & \multicolumn{2}{|c|}{-} \\
\hline 0.62 & 10.8 & 1.3 & 20.2 & 1.3 & 23.1 & 1.0 & \multicolumn{2}{|c|}{ n.d. } \\
\hline 0.55 & 7.8 & 1.2 & 14.6 & 1.4 & \multicolumn{2}{|c|}{ n.d. } & 22.3 & 1.3 \\
\hline
\end{tabular}

TABLE 5: Carbonation coefficients from accelerated and natural exposure $\left(\mathrm{mm} / \mathrm{y}^{1 / 2}\right)$.

\begin{tabular}{lcc}
\hline Mixture & $k_{\text {avg }}$ & $k_{\text {atm }}$ \\
\hline 0.80 & 8.4 & 11.4 \\
0.70 & 8.2 & 9.1 \\
0.62 & 6.7 & 7.1 \\
0.55 & 4.8 & 5.1 \\
\hline
\end{tabular}

depth measured after the conditioning period. The average carbonation coefficient was obtained from

$$
k_{\mathrm{avg}}=\frac{\sum k_{i} \cdot\left(x_{i}-x_{0}\right)}{\left(\sum x_{i}-i \cdot x_{0}\right)} .
$$

Carbonation coefficient has been modeled using the $\mathrm{CO}_{2}$ diffusion coefficient in concrete $(D)$, the $\mathrm{CO}_{2}$ concentration $(c)$, and the concentration of hydrated calcium compounds (M) [3]:

$$
k=\sqrt{\frac{2 D c}{M}} .
$$

In the event of experiments with two different external $\mathrm{CO}_{2}$ concentrations $\left(c_{1}, c_{2}\right)$ using separate specimens of the same concrete mixture, the time to reach a given carbonation depth $x_{c}$ in both specimens would be, for concentration $c_{1}$,

$$
t_{1}=x_{c}^{2} \cdot \frac{M}{2 D c_{1}}
$$

and, for $c_{2}$,

$$
t_{2}=x_{c}^{2} \cdot \frac{M}{2 D c_{2}}
$$

thus, solving for $x_{c}^{2}$,

$$
x_{c}^{2}=\frac{t_{1} 2 D c_{1}}{M}=\frac{t_{2} 2 D c_{2}}{M} ;
$$

solving for $t_{1}$,

$$
t_{1}=t_{2} \frac{c_{2}}{c_{1}}
$$

from (4) and (7),

$$
x_{c}^{2}=t_{1} k_{1}^{2}=t_{2} k_{2}^{2}
$$

substituting (8) in (9),

$$
t_{2} \frac{c_{2}}{c_{1}} k_{1}^{2}=t_{2} k_{2}^{2}
$$

solving for $k_{1}$,

$$
k_{1}=k_{2} \sqrt{\frac{c_{1}}{c_{2}}}
$$

and then, the average carbonation coefficients obtained in (3) were converted to atmospheric carbonation coefficient $\left(k_{\text {atm }}\right)$ using (11):

$$
k_{\mathrm{atm}}=k_{\mathrm{avg}} \sqrt{\frac{c_{\mathrm{atm}}}{c_{4 \%}}},
$$

where $c_{\text {atm }}$ and $c_{4 \%}$ are the atmospheric and $4 \% \mathrm{CO}_{2}$ concentrations, respectively.

The atmospheric carbonation coefficients are also presented in Table 5. According to the literature [5], carbonation coefficients above $6 \mathrm{~mm} /$ year $^{1 / 2}$ are representative of low quality concrete and carbonation coefficients below $3 \mathrm{~mm} /$ year $^{1 / 2}$ are representative of high quality concrete. The carbonation coefficients were above $6 \mathrm{~mm} /$ year $^{1 / 2}$ for specimens from mixtures $0.80,0.70$, and 0.62 , suggesting low quality concrete from the durability point of view but as expected when using the w/c ratios employed. However, carbonation coefficients related to normal quality concrete were obtained for the lowest w/c ratio employed, suggesting 
that durable concrete may be obtained with this material despite the high porosity.

Thus, despite the high porosity of the concrete mixtures, enough compressive strength was obtained and the carbonation coefficients were consistent with the compressive strength's quality of the material.

\section{Conclusions}

(i) High porosity values for concrete, above $22 \%$, were obtained when using high-absorption aggregates.

(ii) Designed compressive strength was achieved up to $30 \mathrm{MPa}$ despite the use of high-absorption aggregates.

(iii) Carbonation coefficients related to normal quality concrete were obtained for concrete mixtures of 0.55 water/cement ratio when using high-absorption aggregates.

\section{Acknowledgments}

The author would like to acknowledge the partial support from CONACyT (Grant J34433-U) and Universidad Autónoma de Yucatán in several stages of this investigation. The opinions and findings of this investigation are those of the author and are not necessarily those of the supporting organizations. The author is indebted to J. Cob, G. Domínguez, F. Duarte, and W. Castillo for performing some of the tests reported in the paper.

\section{References}

[1] L. Véleva, P. Castro, G. Hernández-Duque, and M. Schorr, “The corrosion performance of steel and reinforced concrete in a tropical humid climate: a review," Corrosion Reviews, vol. 16, no. 3, pp. 235-284, 1998.

[2] R. F. M. Baker, "Initiation period," in Corrosion of Steel in Concrete, p. 22, Schiessl, Chapman and Hall, London, UK, 1988.

[3] E. I. Moreno, Carbonation of blended cement concretes [Ph.D. dissertation], University of South Florida, 1999.

[4] E. I. Moreno and A. A. Sagüés, Carbonation-Induced Corrosion on Blended-Cement Concrete Mix Designs for Highway Structures, NACE International, Houston, Tex, USA, 1998, CORROSION/98, paper no. 636 .

[5] O. Trocónis-Rincón, A. Romero-Carruyo, C. Andrade, P. Helene, and I. Díaz, Manual for Inspecting, Evaluating and Diagnosing Corrosion in Reinforced Concrete Structures, CYTED, Maracaibo, Venezuela, 2000.

[6] S. H. Kosmatka and W. C. Panarese, Design and Control of Concrete Mixtures, Portland Cement Association, Skokie, Ill, USA, 14th edition, 2002.

[7] R. Solís-Carcaño and E. I. Moreno, "Evaluation of concrete made with crushed limestone aggregate based on ultrasonic pulse velocity," Construction and Building Materials, vol. 22, no. 6, pp. 1225-1231, 2008.

[8] Standard Practice for Selecting Proportions for Normal Heavyweight, and Mass Concrete, ACI 211.1-91, ACI International, Farmington Hills, Mich, USA, 1997.
[9] Standard Practice for Making and Curing Concrete Test Specimens in the Laboratory, ASTM C 192-98, ASTM International, West Conshohocken, Pa, USA, 2002.

[10] "CPC-18 measurement of hardened concrete carbonation depth," Materials and Structures, vol. 21, pp. 453-455, 1988. 

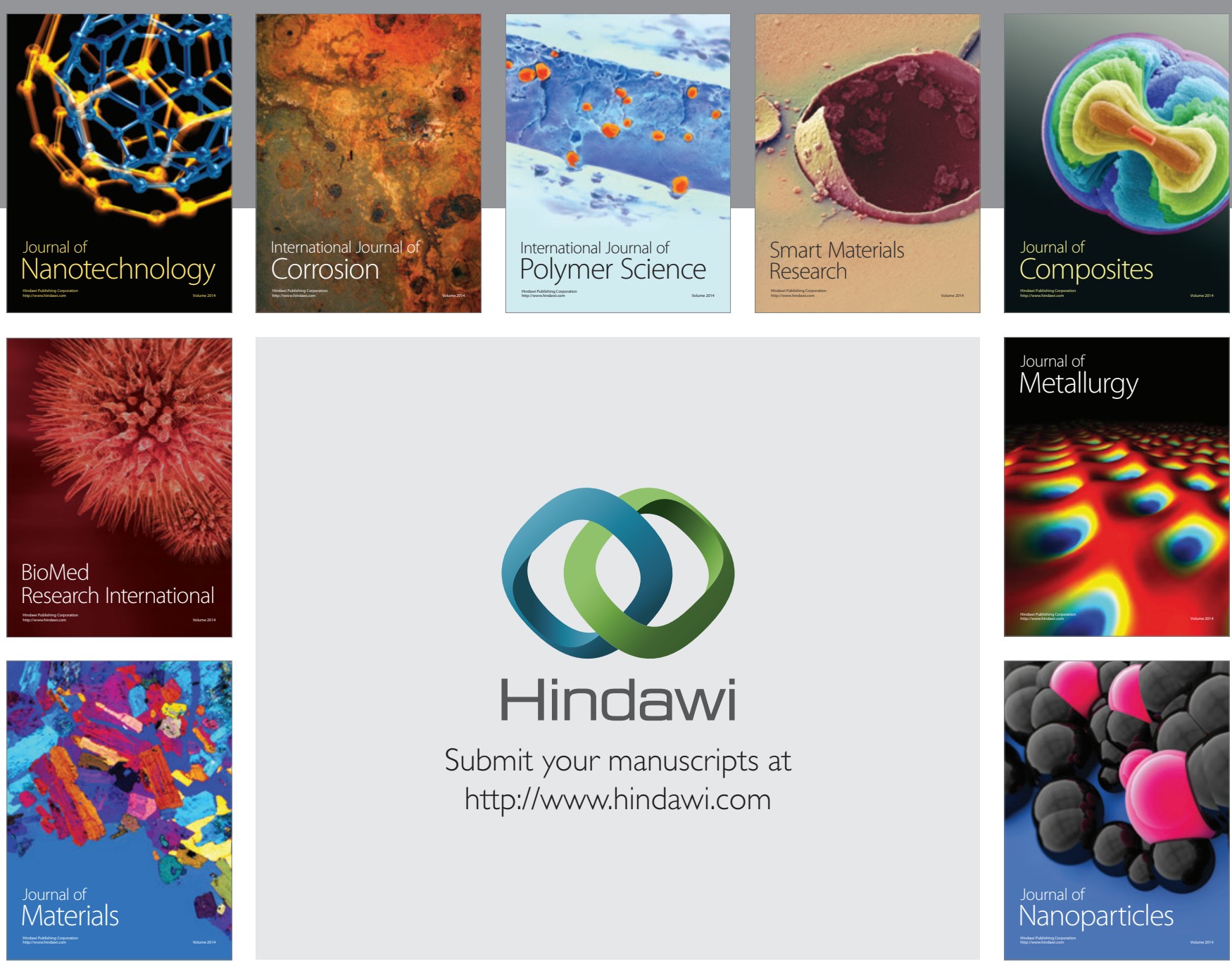

Submit your manuscripts at http://www.hindawi.com
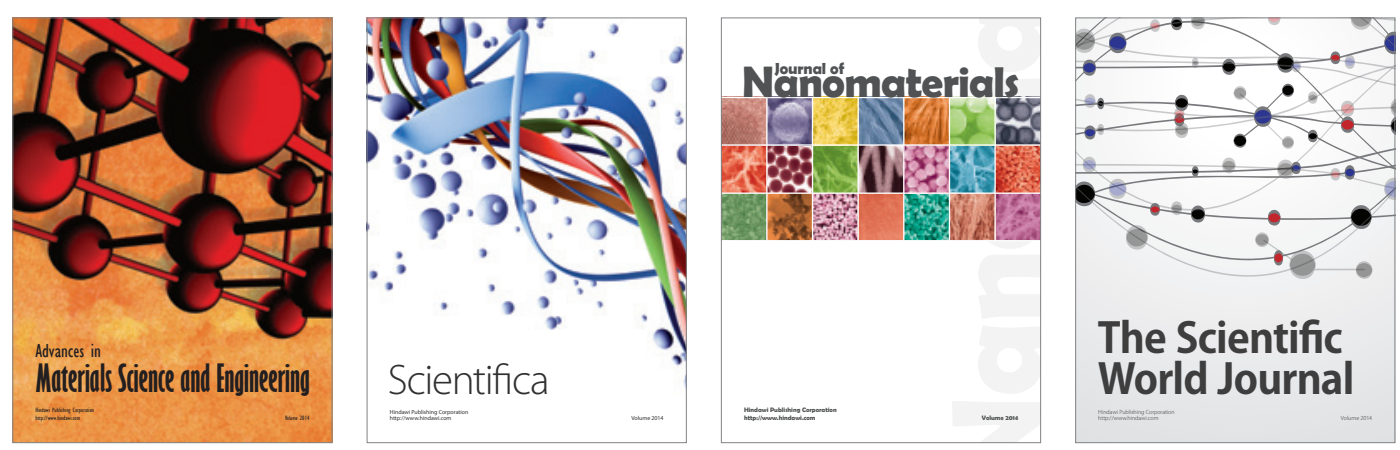

\section{The Scientific World Journal}
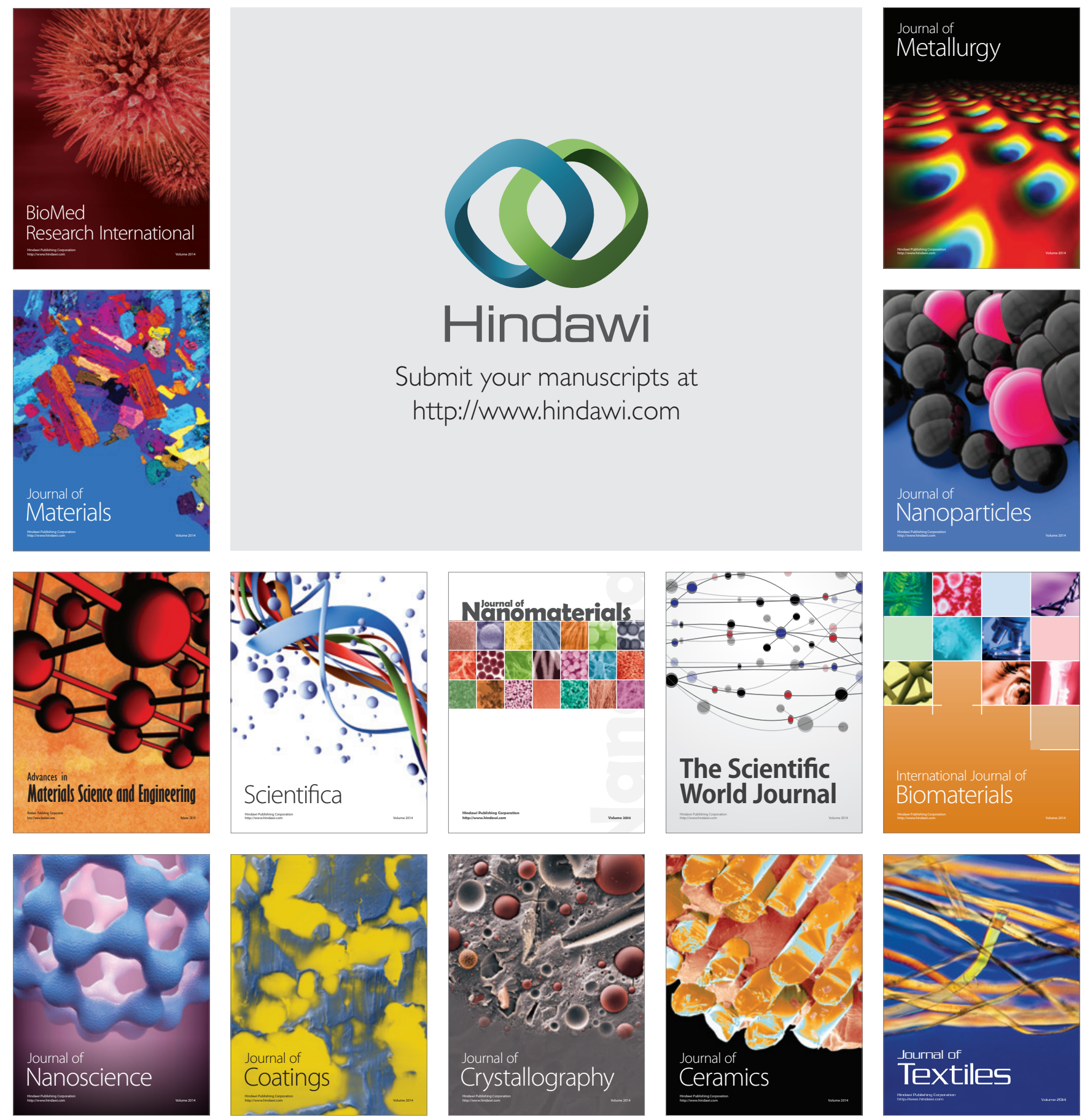